\title{
Trends in the internationalization of European higher education in a convergence perspective
}

\author{
Alina Mihaela DIMA \\ The Bucharest University of Economic Studies, Bucharest, Romania \\ alinamihaeladima@yahoo.com \\ Simona VASILACHE \\ The Bucharest University of Economic Studies, Bucharest, Romania
}

\begin{abstract}
The paper proposes several indicators for the degree of convergence in the internationalization of European higher education, based on previous research on the topic and on the availability of data in the large repositories, such as Eurostat. Starting from longitudinal data series built using the values of the selected indicators in 2015; we have grouped European higher education systems in clusters, based on their similarity, that is, potential for medium term convergence. These findings may serve as a guiding methodology for further, more detailed investigations on convergence and divergence of higher education systems in Europe. The main limitations arise from the availability of data, more specifically from the lack of in-depth data collection at the European level.
\end{abstract}

Keywords: European higher education, higher education, internationalization, convergence, quantitative analysis.

Please cite the article as follows: Dima, M.A. and Vasilache, S. (2016), "Trends in the internationalization of European higher education in a convergence perspective", Management \& Marketing. Challenges for the Knowledge Society, Vol. 11, No. 2, pp. 449-457 DOI: 10.1515/mmcks2016-0008.

\section{Introduction}

The internationalization dimension of higher education is a common topic in the literature and not a very new one (Nicolescu and Pricopie, 2012). Set up in Bologna, the university as institution, evolved in other famous cities of the world as an intercultural space where students and professors from different parts of the world are looking for knowledge (Verger, 1997). In various papers, internationalization of higher education represents the process of integrating intercultural and international dimensions in teaching, research and administrative services in a university (Knight, 2004).

At present, the specificity related to internationalization process is the dynamic rhythm and the new perspectives of this phenomenon. At European level, the internationalization process is not only an education issue but also economical, political, social, cultural and it has many implications in all areas. Most countries developed internationalization strategies in education with various implications for all policies at national level. 
The dynamic evolution of the European Union recognized the need to provide a harmonized educational system able to provide smooth mobility of students and professors, international projects and collaboration, support for any attempt to internationalize the educational activities and finally to build an European identity among the students.

\section{Literature review}

It has been widely recognized that under globalization challenges, universities in higher education across the world must institutionalize an international dimension to produce students capable to meet the complex pressures of globalization and secure the universities' future (OECD, 2010; Horn et al. in Li-Hua, and Wilson, 2011; De Meyer 2012). The benefits of internationalization are underlined by Elkin et al. (2008) who suggests that "the development of higher levels of internationalization may be related to an institution's change from being a teaching intensive, focused on undergraduate study to being more research intensive and more concerned with postgraduate and collegial research"(p. 248).

De Meyer (2012) identified several factors influencing this phenomenon: globalization of business drives students to be prepared for international markets and careers; high speed of technology that stimulate international collaboration on large distances and across organizational boundaries; internationalizing of faculty staff whose career perspective is based on international institution working place; accreditation and evaluation pressures and qualitative standards.

Various authors (Javalgi et al., 2009; Czinkota, 2006) mention that higher education has been often seen as an international trade commodity, where universities, especially those in advanced nations such as USA, UK, Canada, Australia, and New Zealand have been among the largest "exporters" of higher education services, while countries such as India and China have become among the largest suppliers of student "customers" that study at foreign institutions. From a strategic perspective, internationalizing universities may face uniquely high pressures for replication due to the nature of the product/service (Hill, 2007). The value of an international degree, the right to award a degree, the reputation of the provider and the successful delivery of the educational service may all depend on tight integration of offshore activities and an accurate "replication" of the home country model of education (Boyle et al., 2012).

Previous studies in internationalization such as the "star" model of Elkin and Devjee (2003) use various dimensions (undergraduate international students, postgraduate international students, student exchange programs, staff exchanges programs, staff interaction in international context/attendance at international conferences, internationally focused program of study, international research collaboration, support for international students, international institutional links) tested and validated further by Elkin et al (2008).

Kouijzer (1994) identifies some elements that should be included to develop an international strategy, such as international teaching programs, partnerships, students and staff exchanges, and research activities. In addition to these factors, Taylor (2004) has identified other elements as: "development of new disciplines; "recognition of the 
MMCKS importance of customer care and marketing skills; "the importance of centralized management and risk management; "the application of modern technology.

Belcher (1995) analyses some criteria for universities to become more international and Bartell (2003) suggests a variety of indicators in attempting to measure the level of the internationalization process of universities.

Among the drivers of internationalization, some authors see financial incentives as the main stimulus for internationalization (Rudzki, 1998; Poole, 2001); others the international brand name and statutes (Chan, 2004; Ayoubi and El-Habiabeh, 2006) or simply emerging at the faculty level (Brown, 1997; Chaston, 1994)

However, any internationalization process is characterized by limits and benefits. Some barriers to internationalization may include financial issues, cultural problems, development problems or individual commitments (Brown, 1998).

Positive approaches identify internationalization as a good strategy for increasing market characteristics, international image, diversification and opportunities for new income, giving overseas students an opportunity to gain professional knowledge and to experience other cultures and educational systems (Poole, 2004), and to faculty staff more opportunities for interdisciplinary research and enhancement of their experience (Gahungu, 2001).

\section{Methodology}

We have chosen four indicators to characterize convergence in European higher education, from an internationalization perspective. We have used cluster analysis, in order to group European higher education systems based on the four proposed indicators' values: outgoing to incoming students' ratio, share of visiting professors, share of international grants in total funding, and average amount of financial support for students studying abroad. We retrieved data from Eurostat and from the national reports (as of 2015) available on the EHEA website.

We use the City Block (Manhattan) distance measurement, than grouping methods, as k-means (MacQueen, 1967), with 3 centroids, corresponding to education leaders, catchers-on, and clampers on (very advanced countries, whose growth rate in the selected indicators is very low). Relying on literature approaches to convergence (Scaglione and Johnson, 2007) we have set the number of clusters. However, deciding on the exact number of categories remains a challenge (Miron et al., 2009).

The indicators were chosen as to ensure comparativeness between European countries, and to be able to retrieve recent data, that would give an accurate picture of today`s higher education landscape in Europe, faced with its internationalization perspectives. below:

The integrated table, based on data available for all four indicators, is presented 
Table 1. Integrated indicators table

\begin{tabular}{|c|c|c|c|c|c|}
\hline No & Country & I1 & I2 & I3 & I4 \\
\hline 1 & Austria & 0.16 & 4.1 & 0.09 & 11.7 \\
\hline 2 & Belgium & 0.23 & 4.8 & 0.07 & 13.8 \\
\hline 3 & Bulgaria & 1.96 & 1.91 & 0.13 & 7.4 \\
\hline 4 & Cyprus & 2.61 & 4.7 & 0.19 & 55.8 \\
\hline 5 & Czech Republic & 0.31 & 5.7 & 0.16 & 2.9 \\
\hline 6 & France & 0.14 & 2.3 & 0.2 & 7.4 \\
\hline 7 & Germany & 0.37 & 1.6 & 0.18 & 20.7 \\
\hline 8 & Hungary & 0.42 & 3.2 & 0.12 & 14.3 \\
\hline 9 & Ireland & 1.29 & 2.7 & 0.05 & 13.2 \\
\hline 10 & Italy & 0.39 & 2.2 & 0.12 & 22 \\
\hline 11 & Latvia & 1.84 & 6.1 & 0.2 & 12.7 \\
\hline 12 & Lithuania & 2.11 & 4.6 & 0.11 & 15.7 \\
\hline 13 & Malta & 2.37 & 12.6 & 0.24 & 0.3 \\
\hline 14 & Netherlands & 0.33 & 1.8 & 0.18 & 27 \\
\hline 15 & Norway & 1.75 & 2 & 0.01 & 40.9 \\
\hline 16 & Poland & 1.62 & 1.3 & 0.15 & 1.4 \\
\hline 17 & Portugal & 1.06 & 3.6 & 0.06 & 14.7 \\
\hline 18 & Romania & 1.84 & 2.4 & 0.02 & 7 \\
\hline 19 & Slovak Republic & 4.31 & 3.8 & 0.17 & 19.5 \\
\hline 20 & Slovenia & 0.95 & 5.7 & 0.14 & 22.3 \\
\hline 21 & Sweden & 0.31 & 1.7 & 0.02 & 24.9 \\
\hline 22 & UK & 0.05 & 1.3 & 0.37 & 37.5 \\
\hline
\end{tabular}
* Own computations, based on http://ec.europa.eu/eurostat and http://www.ehea.info/articledetails.aspx?ArticleId=73, accessed July 2016

The resulting clusters, by principal component analysis, and distance weighted least squares graphs are presented and discussed in the next section.

\section{Results}

We have performed multiple correspondence analysis, on the four indicators chosen, the results being summarized in the graph below: 


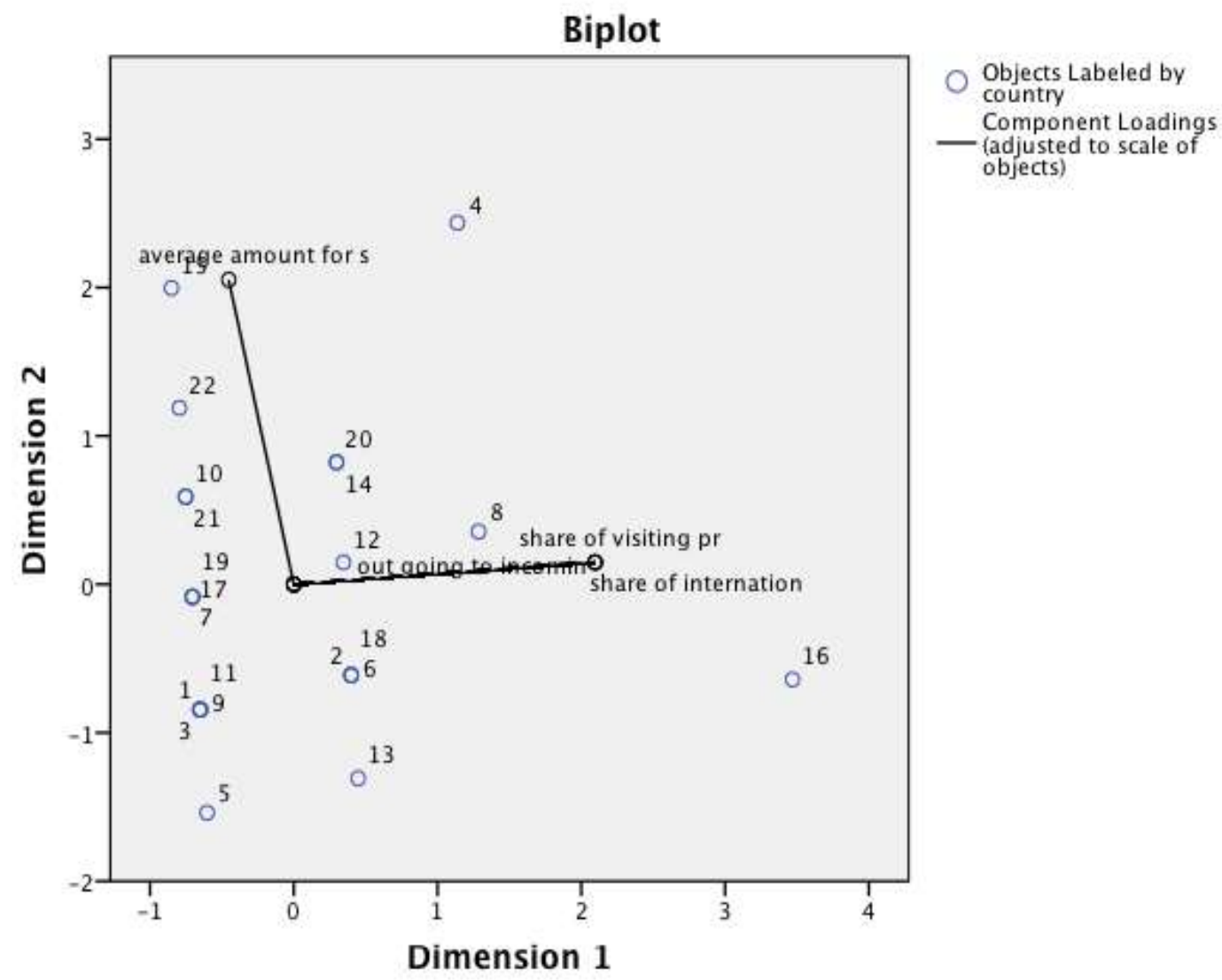

Variable Principal Normalization.

Figure 1. Principal component analysis

Source: Authors' own processing.

It may be seen that, while the indicators relating to mobility and internationally attracted funds are aggregated on the same dimension, the financial support granted to students studying abroad stays apart. Four main clusters and two groups of outliers may be identified on the bi-plot. A first group, ensuring rather significant financial support to students abroad, but exhibiting low levels of mobility, is formed by UK, Italy, Sweden, Slovak Republic, Portugal and Germany. Most of these countries have strong economies, enabling them to support their students, and strong educational systems, which make students rather study at home (UK and Germany are among the most attractive destinations, which makes their outgoing to incoming ratios to be naturally low). These countries are "the developed conservatives", exhibiting low change levels in their behavior.

A second cluster is formed by countries offering a moderate support to students going abroad, whose mobility is high, in terms of students and professors. These countries are Slovenia, Netherlands, Lithuania and Hungary. They are "developing globalizers", which catch up, in terms of relocating students and professors abroad.

The third cluster includes countries which are more oriented towards mobility, than financial support granted to students: Belgium, France, Malta and Romania. They tend to serve a humanistic model, of extensive relationships with the rest of world, while not offering, or not affording to offer too much support to their exchange students. They are "the expanders", much more focused on the outgoing fluxes of students and staff. 
Finally, the fourth cluster is neither oriented towards financial support to students, nor to the mobility of students and professors. These countries are Austria, Bulgaria, Czech Republic, Ireland and Latvia. They are "the expectants", whose situation is likely to change for better or worse in the next decade.

Outliers are Poland, very oriented towards internationalization, and Cyprus, very oriented towards protective financial support. Although the clusters are not very homogenous, at the first sight, due to the structure of indicators, which may mean different things to different contexts, their disposal gives an outlook of trends in European education, orienting studies on convergence. It may be seen that the inter-cluster distances are low, allowing for possible migrations, in the near future. Studying the factors enabling these migrations is one of the themes for further study.

We have obtained tridimensional plots of indicators considered, which are presented, comparatively, for Romania and EU15, in the charts below:

3D Surface Plot of year against fprofRO and fprofEU

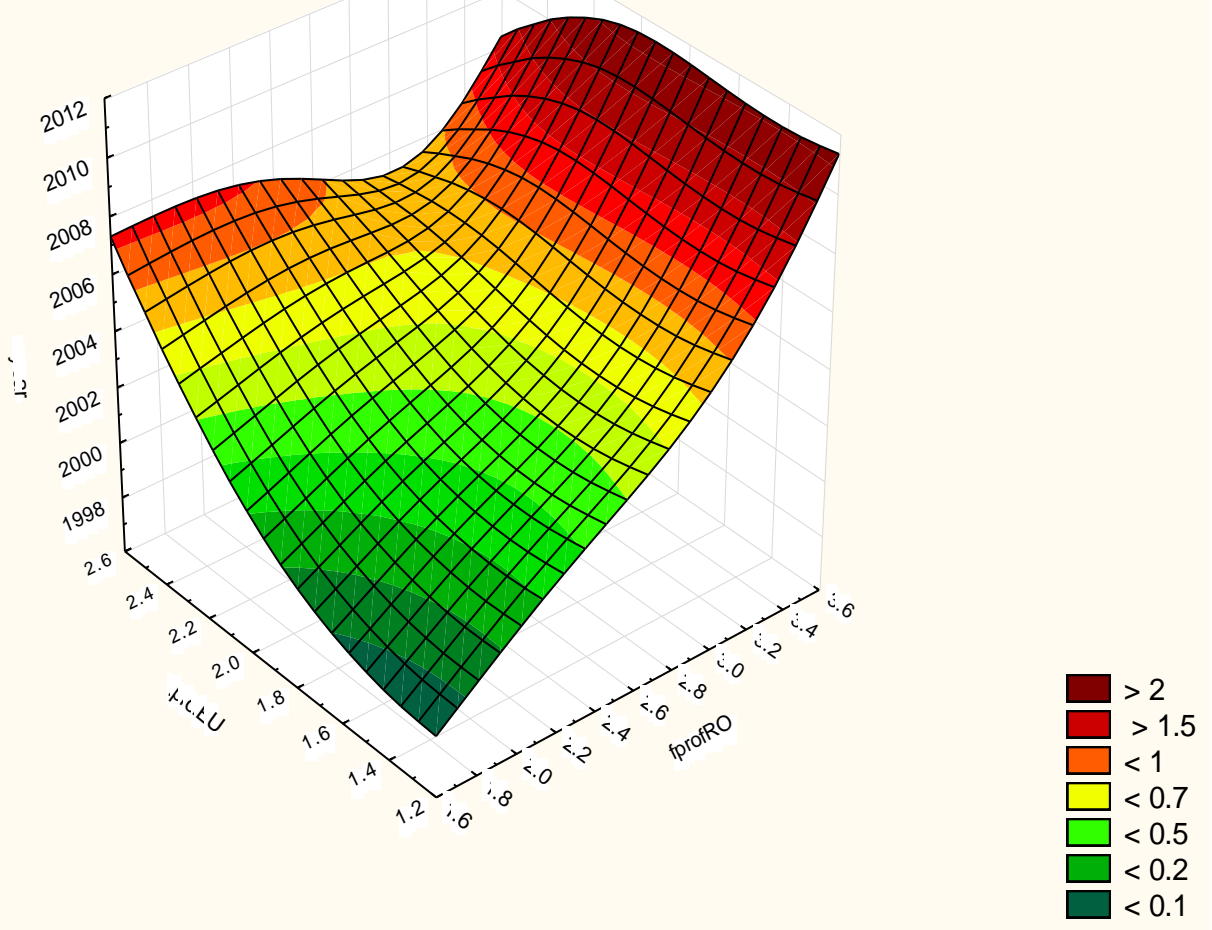

Figure 2. Outgoing to incoming students' ratio yearly dynamics

Source: Authors' own processing.

The ratio of foreign students attracted in Romanian universities (incoming) is well below the European average, due to lack of awareness of Romanian system at the EU level, and the low degree of representativeness (no universities in top 500, no international visibility). On the other hand, Romania is a net exporter of students, migrating to more attractive study destinations in the EU, estimating a better return on educational investment, on a medium to long term. Steps to be taken, in order to reverse the odds, are better marketing strategies and a focus on promoting at least some of Romanian universities in the international top league. 
3D Surface Plot of year against studEU and studRO

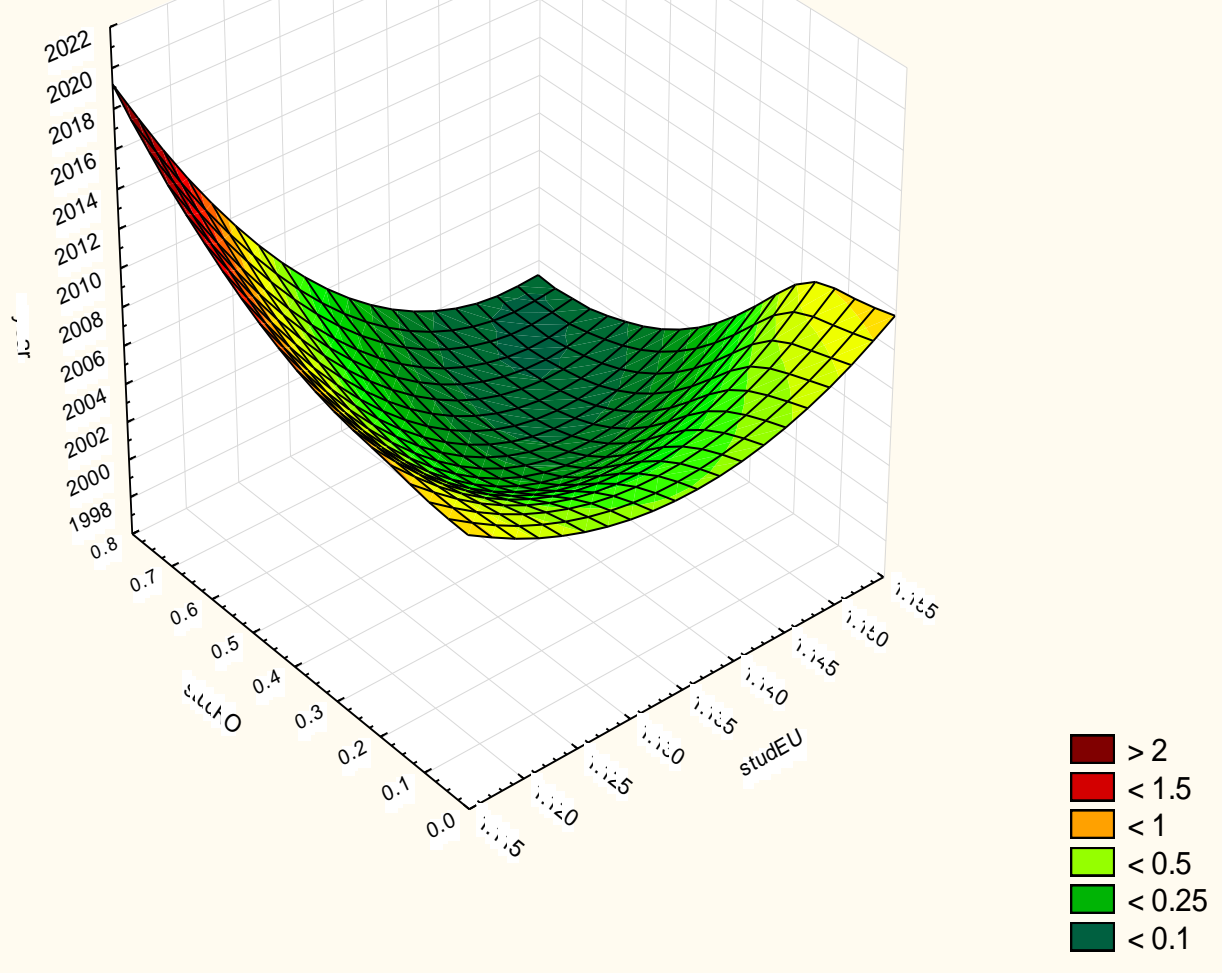

\section{Figure 3. The evolution of the share of visiting professors (Romania as compared to EU)}

Source: Authors' own processing.

The disparity is less obvious in the case of professors than in the case of students, as there are more opportunities for professors to circulate freely in the European space, and their numbers are lower than in the case of students. However, the extent to which their mobility adds to the quality of the teaching process and speeds up convergence remains a topic to be further researched.

\section{Conclusions}

The analysis outlined the main disparities in convergence between a country from Central and Eastern Europe, taken as a case study, and the core of the EU. Also, we have plotted the considered indicators against two axes, outlining the clustering principles, in Europe, and making it, thus, easier to assess convergence levels. Our cluster analysis revealed the existence of four main groups of countries, whose dynamics over time can be considered for 
further forecasts, which take into account changes in external as well as internal higher education environments.

We have used highly visual techniques in order to outline the trends in the mobility of students and staff, in Romania as compared to the rest of the EU. Factors of the observed phenomena were looked for, while there is still place for further research in mapping the entire group of influencers contributing to the acceleration or, on the contrary, the deceleration of international students and professors exchange. As internationalization is a key issue of the Bologna agenda, our research gives a fair insight of where we stand and which would be the near to medium perspectives for improving our inflows and outflows of students and staff.

\section{References}

Ayoubi, R. and El-Habiabeh, A. (2006), "An investigation into international business collaboration in higher education organisations: a case study of international partnerships in four UK leading universities", International Journal of Educational Management, Vol. 20, No. 5, pp. 380-96.

Bartell, M. (2003), "Internationalization of universities: a university culture-based framework", Higher Education, Vol. 45, pp. 43-70.

Belcher, J. (1995), "Thinking globally, acting locally: strategies for universities", Journal of International Education, Vol. 6, No. 3, pp. 5-13.

Boyle, B., McDonnell, A., Mitchell, R. and Nicholas, S. (2012), Managing knowledge in internationalizing universities through foreign assignments, International Journal of Educational Management, Vol. 26 No. 3, pp. 302-312.

Brown, R. (1997), "Developing effective overseas partnerships: lessons from Britain", Journal of International Education, Vol. 8, No. 1, pp. 15-21.

Brown, R. (1998), "Developing effective overseas partnerships: future lessons from Britain", Journal of International Education, Vol. 9, No. 3, pp. 12-19.

Chan, W.E.Y. (2004), "International cooperation in higher education: theory and practice", The strategy of Studies in International Education, Vol. 8, No. 1, pp. 32-55.

Chaston, I. (1994), "Strategies of management in the new UK universities", Higher Education in universities Review, Vol. 26, No. 2, pp. 65-75.

Czinkota, M.R. (2006), "Academic freedom for all in higher education: the role of the general agreement on trade in services", Journal of World Business, Vol. 41, No. 2, pp. 14960.

De Meyer, A. (2012), "Reflections on the globalization of management education", Journal of Management Development, Vol. 31 No. 4, 2012, pp. 336-345

Elkin, G. and Devjee, F. (2003), "Report on internationalization, committee for the advancement of learning and teaching", University of Otago, Dunedin, New Zealand.

Elkin, G., Farnsworth, J. and Templer, A. (2008), "Strategy and the internationalisation of universities", International Journal of Educational Management, Vol. 22, No. 3, pp. 239-250. 
MMCKS Gahungu, A. (2001), "US-Africa cooperation in education at Northern Arizona University: unexpected lessons", Journal of Studies in International Education, Vol. 5, No. 2, pp. 146-64.

Hill, C. (2007), International Business: Competing in the Global Market Place, McGraw-Hill Irwin, New York, NY.

Knight, J. (2004), "Internationalization Remodeled: Definition, Approaches, and Rationales", Journal of Studies in International Education, Vol.8, No.1, pp. 5-31.

Kouijzer, R. (1994), "Internationalization: management and strategic policy development", Higher Education Management, Vol 6, No. 1, pp 99-103.

Javalgi, R.G., Joseph, W.B. and La Rosa, R.J. (2009), "Cross-cultural marketing strategies for delivering knowledge-based services in a borderless world: the case of management education", Journal of Services Marketing, Vol. 23, No. 6, pp.371-384.

Li-Hua, R. and Wilson, J. (2011), "Strategic aspects of innovation and internationalization in higher education. The Salford PMI2 experience", Journal of Chinese Entrepreneurship, Vol. 3, No. 1, pp. 8-23.

OECD (2010), Education at a Glance 2010: OECD Indicators, OECD, Paris.

MacQueen, J. (1967), "Some methods for classification and analysis of multivariate observations", Proceedings of the Fifth Berkeley Symposium on Mathematical Statistics and Probability, Volume 1: Statistics, pp.281-297.

Miron, D., Dima, A. and Paun, C. (2009), "A model for assessing Romania's real convergence based on distances and clusters methods", Economic Computation and Economic Cybernetics Studies and Research, Vol. 1, (15. July), pp. 1-18.

Nicolescu, L. and Pricopie, R. (2012), "Universities in the globalization and European context (Universităţile în contextul europenizării şi globalizării)", Strategic projects for higher education.

Poole, D. (2001), "Moving towards professionalism: the strategic management of international education activities at Australian universities and their faculties of business", Higher Education, Vol. 42, pp. 395-435.

Poole, M. (2004), "Diversity of the student body and social cohesion", paper presented at the 12th General Conference: The Wealth of Diversity, IAU Sao Paulo Conference, July 25-29.

Rudzki, R.E.J. (1998), "The strategic management of internationalization: towards a model of theory and practice", PhD dissertation, University of Newcastle upon Tyne, Newcastle.

Scaglione, M. and Johnson, C. (2007), "Tourism productivity convergence in Europe: Leaders \&Catchers-up. Industry." In P Keller \& T Bieger (Eds) Productivity in Tourism, Erich Schmidt Verlag, Berlin, page 13-25.

Taylor, J. (2004), "Toward a strategy for internationalization lessons and practice from four universities", Journal of Studies in International Education, Vol. 8 No. 2, pp. 149-71

Verger, J. (1997), Patterns In A History of The University in Europe. în Universities in the Middle Ages, Vol. I., edited by H. De Ridder-Symoens, 35-74. Cambridge: Cambridge University Press. 